\title{
O Controller como Gestor da Tecnologia da Informação - Realidade ou Ficção?
}

\author{
Tiago Nascimento Borges \\ Cláudio Parisi \\ Antonio de Loureiro Gil
}

\section{Resumo}

A Tecnologia da Informação (TI) vem aumentando rapidamente a sua participação em todas as áreas de negócios, criando constantemente novos desafios para os gestores das empresas. Neste panorama, espera-se dos profissionais de Controladoria, responsáveis pelo fornecimento e gestão dos sistemas de informações de controle e avaliação de desempenho da empresa, mais do que simplesmente conhecimento em tecnologia. Estes profissionais precisam participar colaborativamente com a área de TI, do processo de gestão da informatização da empresa. Este estudo apresenta uma revisão bibliográfica sobre a Tecnologia da Informação no ambiente organizacional e a necessidade da Controladoria na gestão desta área. Foi realizada, igualmente, uma pesquisa com gerentes da área de Tecnologia da Informação e Controladoria, a fim de se confrontar opiniões sobre o papel do Controller na gestão da Tecnologia da Informação, obtendose alguns resultados interessantes, comentados neste trabalho.

Palavras-chave: controllers; CIOs; controladoria; tecnologia da informação; gestão da tecnologia da informação.

\begin{abstract}
Information Technology has quickly increased its importance in several business areas, creating constantly new challenges for company managers. Within such context, controllers are expected to be responsible for supplying and managing the information control systems as well as evaluating the company performance, instead of simply having good knowledge on technology. All these professionals need to participate deeply into the IT area of a company - that is, in the process of company management computerizing. This study presents a review of specific bibliography concerning Information Technology applied to the company organizational environment and also discusses the necessity of having a Controllership working in this same area management. It has been equally carried out a survey together controlling managers of both Information Technology and Controllership areas in order to collect their opinions on paper about the Controller working in the Information Technology management, and, besides that, some other interesting comments on the results were also taken into consideration in this article.
\end{abstract}

Key words: controllers; CIOs; controllerhip; information technology; information technology's management. 


\section{O Papel da Tecnologia da Informação no Ambiente Organizacional}

O conceito de tecnologia da informação deve ser compreendido como sendo muito mais amplo do que apenas considerá-la como processamento de dados, engenharia de software, informática ou o conjunto de hardware e software, devendo ser considerados aspectos humanos, administrativos e da organização.

Para Laudon e Laudon (2001) o termo Tecnologia da Informação se restringe aos aspectos técnicos como hardware e software. Por outro lado, Stair (1998) utiliza o termo Sistema de Informação baseado em computador para agrupar a coleta, manipulação e processamento de dados em informação, pelos elementos tangíveis (hardware) e intangíveis (software, banco de dados, telecomunicações, pessoas e procedimentos), sendo assim responsável pelo fluxo de trabalho das informações e pessoas envolvidas.

Neste estudo, será utilizado o conceito mais amplo para a Tecnologia da Informação, abrangendo os dois conceitos.

Laurindo (2002) considera que o sucesso da gestão da área de Tecnologia da Informação, seu desenvolvimento, instalação e operação de computadores e sistemas de informação, não depende somente da eficiência (qualidade, exatidão e desempenho) dos equipamentos e softwares, obtida pelos analistas e engenheiros de projetos de tecnologia, dependendo também da eficácia (efeitos), que compatibiliza os objetivos dos sistemas de informação e do uso dos computadores às necessidades da organização e dos usuários finais. Já a eficácia da Tecnologia da Informação depende de sua organização estrutural e da empresa, podendo influir na própria mudança estratégica do negócio.

\section{A Evolução da TI nas Organizações}

Embora a TI esteja ocupando uma parte da agenda estratégica das empresas atualmente, este não é fato recente. Segundo Laurindo (2002), durante os anos 60 a utilização da TI era caracterizada por sistemas centralizados, cujo principal objetivo era o de automatizar funções operacionais em larga escala com a finalidade de aumentar a eficiência das operações, sendo utilizados basicamente para automatizar processos, como contabilidade e folha de pagamentos. No início dos anos 70, com a redução no custo e aumento da velocidade de processamento, foi possível utilizar 
os computadores para fornecer relatórios gerenciais. Iniciou-se o uso dos dados (de pedidos, clientes, estoques etc.) pelos gerentes de nível médio, envolvidos em relatar as exceções, resumir as informações e controlar os recursos monetários e estoques. Neste momento, a Era dos Sistemas de Informação, a TI começou a aumentar sua importância nos níveis intermediários da organização, embora a alta gerência ainda visse a TI como despesa ou como mera utilidade.

Com o advento dos microcomputadores no início dos anos 80, houve mudança de paradigma na computação empresarial. Os dados, antes centralizados nos mainframes, passaram a ser colocados nas mesas dos usuários e gerentes. Embora a expertise continuasse no departamento de TI, o controle moveu-se, mesmo que marginalmente, em direção aos usuários. Ainda que a TI atingisse os níveis mais altos da organização, seu foco estava no aumento da eficiência interna e no aumento da produtividade pessoal. A partir do meio da década de 80, muitos sistemas de informação, desenvolvidos em empresas, foram reconhecidos como estratégicos por terem apresentado impactos na competitividade de empresas.

Nos anos 90, a TI tomou conta das corporações, e aspectos como o alinhamento da TI aos negócios e a convergência da informática com as telecomunicações tornaram-se prementes para as empresas. Iniciou-se então a Era da Tecnologia da Informação. A importância estratégica da TI foi definitivamente incorporada nas empresas, que procuraram novas maneiras de administrá-la, a fim de obter plenamente seus benefícios, com a terceirização como uma das alternativas. No final da década, a Internet reforçou essa tendência, e presenciou-se o nascimento do e-business, que sem dúvida marca o início de nova era na computação empresarial.

\section{A Necessidade de TI nas Organizações}

A partir do histórico de utilização exposto, pode-se afirmar que o principal motivo pelo qual as empresas utilizam a TI é a busca de vantagens competitivas. Desde o princípio de sua utilização, buscava-se obter essa vantagem pela redução de custos por meio da automação e aumento da eficiência de processos. Posteriormente, buscou-se a melhoria da qualidade das informações disponíveis para os gerentes médios, de maneira que pudessem controlar melhor as operações. Em uma etapa seguinte, buscava-se utilizar a TI para gerar diferenciação competitiva, como a criação de barreiras de entrada ou elevação dos custos de substituição por meio dos então chamados sistemas estratégicos. A redução de custos, a melhoria no controle dos processos e a utilização de sistemas estratégicos estão diretamente ligadas à busca pela melhoria da competitividade da empresa. 
Mais recentemente, a integração das atividades da empresa por meio da chamada computação em rede busca melhorias na competitividade, beneficiando-se da melhor coordenação entre as diversas atividades da empresa.

Finalmente, em cenário atual, em que a globalização, o aumento da competitividade e a interligação de clientes e fornecedores em cadeias de suprimento são preponderantes, a utilização de Tecnologia da Informação pode ser considerada praticamente como fator de sobrevivência. John Darwin (2004) destaca que a maioria dos gestores de Tecnologia da Informação executa hoje quatro trabalhos: atuando na liderança das equipes da companhia, planejando (acompanhando as tecnologias, possibilitando a arquitetura e ajustando-a aos orçamentos), gerenciando projetos específicos e coordenando as operações em TI; no entanto, isso só poderá ser consolidado, se houver a efetiva integração dessa área com o negócio em que ela esteja estabelecida.

\section{A Atuação da Controladoria nas Organizações}

A controladoria surgiu no início do século XX em grandes corporações norteamericanas, estas fortemente influenciadas por três fatores que marcaram o desenvolvimento industrial daquela época: verticalização, várias empresas com controle centralizado; diversificação, grupos atuando em segmentos diversos do mercado; e expansão geográfica, a globalização dos mercados tinha início.

\section{Missão da Controladoria}

A missão da controladoria é dar suporte à gestão de negócios da empresa, de modo a assegurar que esta atinja seus objetivos, cumprindo assim sua missão.

Mosimann e Fisch (1999) ressaltam que a Controladoria tem a obrigação de empregar todas as suas forças para certificar-se do cumprimento da missão e da continuidade da empresa. Desse modo, ela permite a coordenação de esforços para chegar-se a um resultado global sinérgico, isto é, chegar-se a um efeito acima da soma dos resultados das áreas da empresa.

Assim, pode-se dizer que a sua missão é a de otimizar os resultados econômicos da empresa, interagindo com as demais áreas, visando sempre à sua continuidade.

Almeida, Parisi e Pereira in Catelli (1999) também destacam como missões da 
Controladoria: (a) permitir e aperfeiçoar a aplicação, dentro do ambiente da empresa, dos conceitos de gestão econômica; e, (b) otimizar os resultados da empresa.

O valor agregado pela Controladoria à empresa redunda na diferença dos resultados que esta obtém entre ter Controladoria e não tê-la.

Portanto a Controladoria, para poder cumprir, de maneira coerente e satisfatória, a sua missão, tem como objetivos: (a) promoção de eficácia organizacional; (b) viabilização de gestão econômica; e, (c) promoção de integração das áreas de responsabilidades da empresa.

Conseguir estes objetivos é obter os resultados econômicos, derivados de metas e condições previamente estabelecidas, advindas de tomadas de decisões, provenientes da gestão econômica.

Assim, o objetivo maior da Controladoria, de acordo com Catelli (1999, p. 373), é "a gestão econômica, compreendida pelo conjunto de decisões e ações orientado por resultados desejados, mensurada segundo conceitos econômicos”.

\section{Funções da Controladoria no Contexto da Tecnologia da Informação}

Almeida, Parisi e Pereira in Catelli (1999, p. 375-376) ressaltam que as funções são atos que, quando desempenhados, se referem a objetivos. Refletindo sobre isto, eles continuam focalizando especificamente a Controladoria, cujas funções estão relacionadas ao conjunto de objetivos e estes, por sua vez, atrelados à sua missão. Dentre as funções principais da área, duas são as que mais se destacam dentro do contexto da Tecnologia de Informação, a saber:

a) Subsidiar o processo de gestão e avaliação de desempenho: a Controladoria provê toda a comunidade de gestores de informações sobre o desempenho e resultado econômico de cada uma das áreas. Esta função também absorve a supervisão da elaboração de orçamentos em TI e sua consolidação com as demais áreas da empresa.

b) Administrar os sistemas de informações: estabelece a base de dados para organizar a informação essencial à gestão e elabora, para os gestores das áreas, modelos de decisão relativos aos mais diversos eventos obtidos destes sistemas, padronizando as informações econômicas que vêm a ser o modelo de decisão da empresa. 


\section{A Atuação da Controladoria na Gestão da Tecnologia da INFORMAÇÃO}

Para Manãs (2001), a gestão da Tecnologia da Informação constitui a aplicação das técnicas de gestão em apoio a processos de inovação tecnológica. Integra princípios e métodos de gestão (administração), avaliação, economia, engenharia, informática e matemática aplicada. Na Gestão Tecnológica, identificam-se as necessidades e as oportunidades tecnológicas; também é onde as soluções tecnológicas são planejadas, desenhadas, desenvolvidas e implantadas, constituindo-se num processo administrativo das atividades da pesquisa tecnológica, assim como da transferência dos seus resultados às unidades produtivas. O que é importante para a competitividade (e a produtividade) é a capacidade de se demarcar os desenvolvimentos tecnológicos (inovação, progresso técnico) dentro de uma estratégia da empresa.

Neste sentido, esta área integra a visão de estratégia, liderança e empreendedorismo. Estratégia, enquanto obtenção da vantagem concorrencial da tecnologia utilizada, em face do desenvolvimento dos Sistemas de Informações; liderança, aquela que se obtém por meio da influência nas pessoas do grupo empresarial, no sentido de levá-las a realizar os objetivos estabelecidos, também atuando com empreendedorismo necessário, quando se está introduzindo mudanças nos processos da organização, ou seja, na implantação de novas tecnologias, por exemplo.

Embora as duas áreas - Tecnologia da Informação e Controladoria - possuam objetivos e metodologias distintas, a convergência de esforços é direcionada aos interesses da continuidade do negócio, em que ambas possuem papel decisivo para seu sucesso.

Um registro empírico desta convergência de interesses pode ser verificada em uma pesquisa realizada no ano de 1996, onde Raghavan Rajaji (então Controller da BancTec Ind, localizada no Estado americano do Texas) promoveu um debate entre Controllers e Gerentes de Tecnologia da Informação de empresas americanas e canadenses, discutindo suas opiniões sobre os problemas normalmente compartilhados pelas áreas. No curso da discussão estes executivos apontaram que a área de Finanças representa mais um modelo para departamentos de Tecnologia da Informação que impedimentos para seu desenvolvimento. Neste sentido, pode-se concluir que os interesses dos gestores da Tecnologia da Informação são, em grande parte, interesses dos gestores de Controladoria das organizações e, deste modo, tornar-se-ia necessário estabelecer parâmetros de interesse e auxílio entre as duas áreas. 
Por meio da pesquisa bibliográfica, relacionamos alguns aspectos da Gestão da Tecnologia da Informação, em que podemos identificar a contribuição da Controladoria no seu desenvolvimento. Estes tópicos são discutidos a seguir.

\section{Gestão das Estratégias de Utilização da Tecnologia de Informação}

A necessidade de alinhamento estratégico da utilização da Tecnologia da Informação, visando à continuidade dos negócios da organização em face da concorrência, requer do gestor de TI capacidade de avaliar sua contribuição no resultado global do negócio.

Russ Banham (2003) aponta como principal dificuldade para este alinhamento, a distância entre o gestor da área de TI e o principal executivo da empresa (Chief Executive Office - CEO). O autor cita uma pesquisa realizada pela consultoria Maintay Partners com 450 companhias norte-americanas, onde se verifica que estas empresas estão gastando, em geral, 25\% a mais com Tecnologia da Informação que seus orçamentos indicam. A pesquisa justifica estes números, considerando principalmente a falta do alinhamento dos gastos com as estratégias de cada negócio. Segundo 57\% dos entrevistados na pesquisa, isso se deve à falta de envolvimento da área de TI com o planejamento dos negócios; segundo outros 82\%, devido às dificuldades de comunicação entre as áreas.

Marianne (2002) cita uma pesquisa realizada pelo Grupo Gartner com 1500 Gerentes de TI no ano de 2002, em que apenas 42\% dos CIOs entrevistados se reportavam diretamente à diretoria das empresas. Isto indica que os fundamentos de integração da área com o negócio ainda são fornecidos por outras áreas de negócio que não a Direção da empresa.

Neste sentido, a Controladoria deve fornecer ao gestor de TI fundamentos contábeis e econômicos, tais como: custos, orçamentos e demais fundamentos de Gestão por Unidades de Negócios, favorecendo a comunicação entre as áreas.

\section{Gestão do Banco de Dados}

Segundo Laudon e Laudon (2001, p. 170), “os sistemas de bancos de dados requerem que a organização reconheça o papel estratégico da informação e comece a gerenciar e planejar a informação como recurso corporativo”. Neste sentido, o gestor de TI, responsável pela administração dos dados da empresa, precisa integrar os conceitos para a modelagem, construção e gestão das bases de dados individuais e corporativas com as demais áreas da companhia. 
Araújo (2003) exemplifica, por meio da proposição de um modelo lógico de banco de dados para uma contabilidade de partida múltipla, o estreito relacionamento entre as necessidades organizacionais e o papel da Tecnologia na concepção de soluções que atendam estas necessidades.

Neste sentido, a Controladoria, como unidade centralizadora da informação, deve trabalhar em conjunto com a área de TI, no planejamento e modelagem destes dados, até mesmo participando no processo de seleção de tecnologias de Data Warehousing e Data Mart, entre outras, devido à função estratégica desses aplicativos.

\section{Gestão de Recursos Humanos e Comportamento Organizacional}

A gestão de recursos humanos requer uma integração entre as diversas áreas de conhecimento da organização, a fim de alinhar interesses individuais com o retorno do investimento global da empresa.

A administração, avaliação, treinamento, desenvolvimento e compensação de recursos humanos subordinados à área de TI necessita do acompanhamento da Controladoria, devido ao seu estreito relacionamento com esta unidade administrativa e, principalmente, devido à necessidade dos profissionais de TI de assimilarem os processos da organização compreendidos pela Controladoria, porquanto, segundo Wang (1995), são muitos os executivos que vêem a tecnologia da informação como a automação de processos manuais. Isto se deve, principalmente, à falta de integração com as outras áreas da empresa.

Oliveira e Riccio (2003) citam também a participação da Controladoria na concepção de instrumentos para mensurar a satisfação dos usuários de sistemas de informações, pois os gestores devem fazer uso destes instrumentos para obter maiores êxitos na utilização destes sistemas (com menores riscos) uma vez que os recursos existentes são escassos.

\section{Métricas Aplicadas à Tecnologia de Informação}

Assim como as demais unidades administrativas da organização, a área de TI necessita de acompanhamento quanto à sua eficiência e eficácia. Para isso, os gestores precisam utilizar modelos de métricas para avaliar estas áreas. 
Entre vários modelos existentes, como o Balanced ScoreCard e Function Points, Laurindo (2002), destaca o benchmarking, obtido por meio de levantamento efetuado em grandes empresas. Neste sentido, cabe à Controladoria estabelecer a relação entre as métricas físicas e as monetárias das diversas companhias para auxiliar a gestão de TI na escolha, implementação e acompanhamento destas métricas.

\section{Gestão da Segurança}

A segurança e o controle dos sistemas de informações requerem o comprometimento de todos os envolvidos no processamento de dados. Laundon e Laundon (2001) atribui ao gerente de TI a adoção de metodologias adequadas à redução das contingências e dos riscos e ameaças às organizações, combinando medidas manuais e automatizadas que, juntas, correspondem ao efetivo controle.

Neste sentido, a Controladoria, como unidade administrativa responsável pelo controle dos sistemas de informações, apóia a gestão da TI na implementação de políticas e procedimentos que contribuem para a eficácia do sistema.

Imoninana (2003) sugere, também, a estreita relação entre as carreiras de Auditor da Tecnologia de Informação e Finanças, onde, por meio de uma pesquisa realizada em 60 faculdades brasileiras, observou-se maior aptidão dos graduandos em Ciências Contábeis para o desenvolvimento de uma carreira como auditor de TI que os graduandos em ciências da computação. O resultado desta pesquisa corrobora a contribuição dos profissionais de Finanças no aspecto de segurança da TI.

\section{Gestão Sistemas Integrados}

Cada dia surge nova tecnologia voltada para a gestão do negócio. Cabe à Controladoria fornecer subsídios para escolha, implantação e acompanhamento de soluções voltadas para a gestão do relacionamento com clientes (CRM), a integração com os sistemas integrados de gestão (ERP) e a gestão da cadeia de suprimentos (SCM), por exemplo.

Segundo Peleias (2000), a implementação de sistemas integrados devem fazer parte do processo de mudança organizacional; portanto a definição sobre a seleção e utilização destas ferramentas de informática deve sempre estar subordinada à resolução dos problemas de gestão das empresas que, neste contexto, são levantados pela área de Controladoria das organizações. 


\section{Gestão de E-Business}

Além dos conceitos de mercado eletrônico e de suas categorias, cabe ao gestor da Tecnologia da Informação avaliar o desempenho de um comércio eletrônico, abrangendo o estudo de modelos de negócio, de comportamento de usuário e de recursos. Neste sentido, os conhecimentos da Controladoria estão voltados para a mensuração e acompanhamento destes investimentos.

Laundon e Laundon (2001) apontam também que, no ambiente E-Business, os negócios sofrem interferências tributárias que podem inviabilizar projetos de implementação de novas tecnologias, e cabe à Controladoria acompanhar estes projetos, apontando alternativas que viabilizem o negócio.

\section{Gestão de Documentos}

Segundo Cruz (1998), a informática possibilita a gestão da informação existente sob a forma eletrônica, em termos do seu ciclo de vida dentro das organizações (Workflow), potenciando a indexação e arquivo da documentação, previamente existente em papel ou em qualquer outro suporte. Caso se alie a esta vertente a publicação desta informação de uma forma global, acessível por todos dentro da organização, verifica-se a interferência da Controladoria na gestão destes processos, uma vez que a necessidade de controle dos documentos físicos (fiscais) e necessidade de obtenção/divulgação de informações são de sua responsabilidade.

\section{Gestão de Contratos}

Segundo Jamil (2001), o suporte para a Tecnologia da Informação é composto de muitos recursos. Hardwares, softwares e serviços são constantemente adquiridos por meio de contratações de variáveis tipos (compra, aluguel, leasing), cobrando do gestor a capacidade de negociação e avaliação destes contratos.

Neste sentido, o empenho e competência com que se negociam contratos são um grande determinante da saúde financeira de qualquer empresa; no entanto a forma como se efetua o acompanhamento da sua execução pelas partes envolvidas, as suas responsabilidades, as ações que são necessárias de serem executadas e as renovações e extensões que precisam ser negociadas e controladas pode ainda ser mais importante para a sobrevivência da organização.

Os contratos na área da Tecnologia da Informação, pelos valores que representam, e porque envolvem compras de tecnologia e de serviços com muitas 
fases de implantação, exigem da Controladoria a construção de abordagem de planejamento financeiro muito adequada à necessidade da organização.

\section{Metodologia de Pesquisa}

Esta pesquisa é de natureza exploratória; portanto encontra-se nos primeiros estágios de investigação científica, permitindo que novas discussões ou análises sejam iniciadas, a partir dos aspectos aqui abordados. Os procedimentos metodológicos do trabalho dividiram-se em duas fases: a primeira desenvolveu, por meio da Revisão Bibliográfica, o cenário da pesquisa e os aspectos que fundamentaram a construção do instrumento para coleta de dados. A segunda fase do trabalho envolveu a coleta de dados, análise e as considerações finais, que serão detalhadas a seguir.

\section{Seleção da Amostra}

Neste estudo, foi realizada uma pesquisa quantitativa descritiva junto a gerentes da área de Controladoria e Tecnologia da Informação de empresas de atuação local, nacional e global (multinacionais) no âmbito das cidades de São Paulo, Campinas, Sorocaba e região. A seleção de profissionais de Controladoria e Tecnologia se fez necessária para diminuir o risco de viés considerado em pesquisas desta natureza.

O processo de amostragem empregado foi de natureza probabilística, com a seleção aleatória de profissionais a partir de listas de estudantes de Mestrado e MBA de cursos relacionados às áreas de Tecnologia e Controladoria. O aspecto da seleção dos respondentes - alunos de Mestrado e MBA - também surgiu da necessidade de se diminuir o viés das respostas, em virtude da possibilidade de maior conhecimento e atualização destes profissionais.

\section{Técnica de Coleta de Dados}

Um questionário composto por 12 (doze) afirmações a que o participante responderia concordando ou não, numa escala Likert, foi disponibilizado no site www.contabilidadeestrategica.hpg.com.br/teste.htm, no período de 30 de julho a 08 de agosto de 2003. 
O questionário foi estruturado conforme os aspectos identificados na pesquisa teórica, composto pelas afirmações relacionadas na Tabela 1:

\section{Tabela 1: Afirmações Submetidas às Opiniões dos Respondentes}

\begin{tabular}{|c|c|}
\hline Aspecto & Afirmação \\
\hline \multirow[t]{2}{*}{$\begin{array}{l}\text { Gestão das Estratégias de } \\
\text { utilização da Tecnologia } \\
\text { de Informação }\end{array}$} & $\begin{array}{l}\text { 1) A controladoria contribui com o processo de definição de conceitos e métodos para } \\
\text { a gestão da área de TI de forma integrada em relação à organização e aos negócios da } \\
\text { empresa. }\end{array}$ \\
\hline & $\begin{array}{l}\text { 2) A controladoria enfatiza a necessidade do alinhamento estratégico da TI e sua } \\
\text { contribuição para o retorno de investimentos em tecnologia pela empresa. }\end{array}$ \\
\hline \multirow[t]{2}{*}{$\begin{array}{l}\text { Gestão de Banco de } \\
\text { Dados }\end{array}$} & $\begin{array}{l}\text { 3) A Controladoria fornece conceitos para a modelagem, construção e gestão das } \\
\text { bases de dados individuais e corporativas pelos profissionais de TI. }\end{array}$ \\
\hline & $\begin{array}{l}\text { 4) A Controladoria participa do processo de escolha, implantação e acompanhamento } \\
\text { das ferramentas de Data Warehousing e Data Mart, assim como na seleção das } \\
\text { tecnologias disponíveis no mercado. }\end{array}$ \\
\hline \multirow{2}{*}{$\begin{array}{lr}\text { Gestão de recursos } \\
\text { Humanos } \\
\text { Comportamento } \\
\text { Organizacional }\end{array}$} & $\begin{array}{l}\text { 5) A Controladoria fornece suporte à área de TI na administração, avaliação, } \\
\text { compensação e no treinamento e desenvolvimento de recursos humanos subordinados } \\
\text { à essa área. }\end{array}$ \\
\hline & $\begin{array}{l}\text { 6) A Controladoria atua como órgão motivador dos recursos humanos a ela } \\
\text { subordinados e envolvidos em projetos da área de TI. }\end{array}$ \\
\hline $\begin{array}{lr}\text { Métricas Aplicadas } & \text { à } \\
\text { Tecnologia } & \text { de } \\
\text { Informação } & \end{array}$ & $\begin{array}{l}\text { 7) A Controladoria auxilia a área de TI no uso de métricas para gestão de áreas de } \\
\text { negócio, tais como Benchmarking e BSC. Também participa na seleção e } \\
\text { implementação destas métricas, integrando as métricas físicas e as monetárias, } \\
\text { principalmente as utilizadas pela engenharia econômica. }\end{array}$ \\
\hline Gestão da Segurança & $\begin{array}{l}\text { 8) A Controladoria fornece conceitos necessários para a implementação de uma } \\
\text { estrutura de controle para TI, participando junto à área de auditoria de sistemas, na } \\
\text { adoção de metodologias adequadas à redução das contingências em TI e dos riscos e } \\
\text { ameaças às organizações. }\end{array}$ \\
\hline $\begin{array}{l}\text { Gestão dos Sistemas } \\
\text { Integrados }\end{array}$ & $\begin{array}{l}\text { 9) A Controladoria participa do processo de escolha, implementação e } \\
\text { acompanhamento de tecnologias de gestão voltadas à integração dos sistemas de } \\
\text { informação, tais como ERP, EIS, SCM, BI, CRM, entre outros. }\end{array}$ \\
\hline Gestão de E-Business & $\begin{array}{l}\text { 10) A Controladoria presta suporte à gestão da TI na mensuração e acompanhamento } \\
\text { de projetos de e-business (planejamento tributário, por exemplo). }\end{array}$ \\
\hline Gestão de Documentos & $\begin{array}{l}\text { 11) A Controladoria auxilia a área de TI na gestão da informação existente sob a } \\
\text { forma eletrônica, em termos do seu ciclo de vida dentro das organizações (Workflow) } \\
\text { e na indexação e arquivo da documentação previamente existente em papel ou em } \\
\text { qualquer outro suporte (Gestão Documental). }\end{array}$ \\
\hline Gestão de Contratos & $\begin{array}{l}\text { 12) A Controladoria fornece o suporte necessário à TI nos processos de terceirização } \\
\text { e gestão de contratos de fornecimento de serviços e equipamentos, na viabilidade } \\
\text { financeira, controle do faturamento através de procedimentos de medição e } \\
\text { acompanhamento. }\end{array}$ \\
\hline
\end{tabular}

\section{Caracterização da Amostra}

Foram contatados 80 participantes, e obteve-se uma amostra de 22 observações, sendo 64\% de gerentes da área de Controladoria e 36\% de gerentes da área de Tecnologia da Informação. No Quadro 1, é apresentada a distribuição de respondentes por qualificação. 


\section{Quadro 1: Qualificação dos Respondentes}

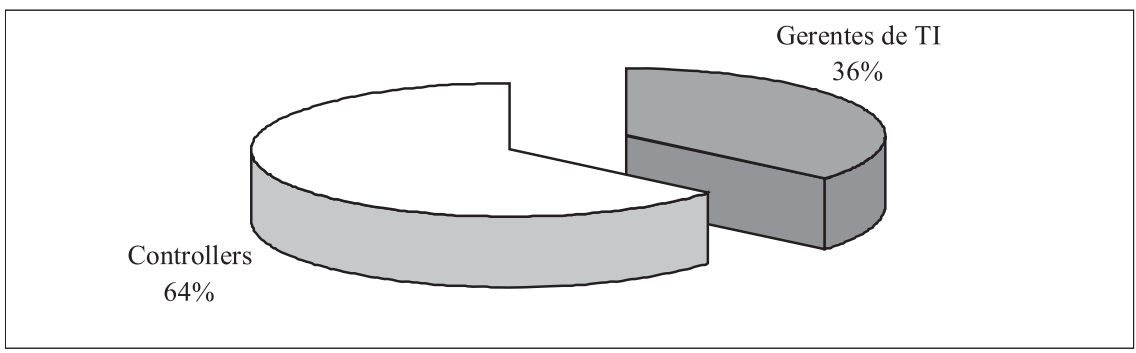

A pesquisa também caracterizou as empresas onde estes profissionais atuam, correspondendo $64 \%$ de empresas com faturamento superior a R \$ 100 milhões por ano. Do total de empresas, metade delas são do ramo industrial, e a origem do capital de todas as empresas é proporcionalmente nacional e estrangeiro. No Quadro 2, é apresentada a qualificação das empresas representadas pelos respondentes ao questionário.

\section{Quadro 2: Perfil das Empresas Representadas no Questionário}
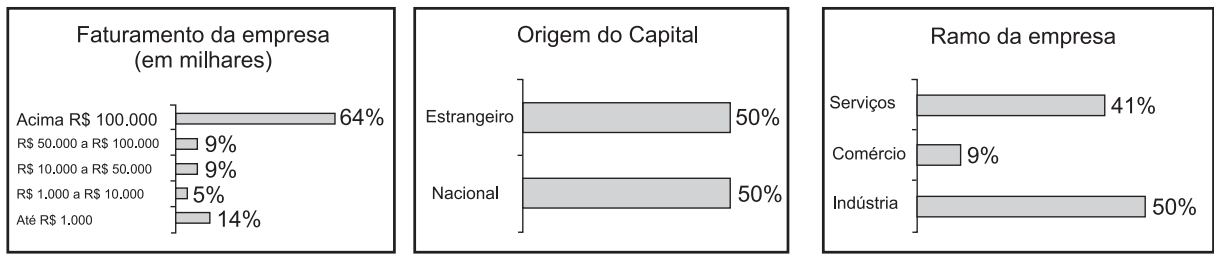

\section{Análise do Resultado da Coleta de Dados}

A partir dos resultados da pesquisa, buscou-se identificar dentre as variáveis da participação da Controladoria na gestão da Tecnologia da informação aquelas que mais são aceitas pelos profissionais de Controladoria e aquelas que mais são aceitas pelos profissionais de Tecnologia da Informação.

Focalizando-se a Gestão das Estratégicas de utilização da Tecnologia da Informação, destaca-se que $88 \%$ dos profissionais concordam que a Controladoria contribui com o processo de definição de conceitos e métodos para a gestão da área de TI de forma integrada em relação à organização e aos negócios da empresa, enfatizando a necessidade do alinhamento estratégico da TI e sua contribuição para o retorno de investimentos em tecnologia pela empresa. E segundo Marianne (2002), uma das maiores dificuldades que os executivos em TI enfrentam atualmente é exatamente a de justificar os enormes gastos com tecnologia. 
Como pode ser observado nos Quadros 3 e 4, a Controladoria está atuando como unidade administrativa responsável pela integração dos gestores da organização, alinhando o Planejamento Estratégico com o Modelo de Gestão da organização.

\section{Quadro 3: Gestão das Estratégias de Utilização da Tecnologia de Informação}

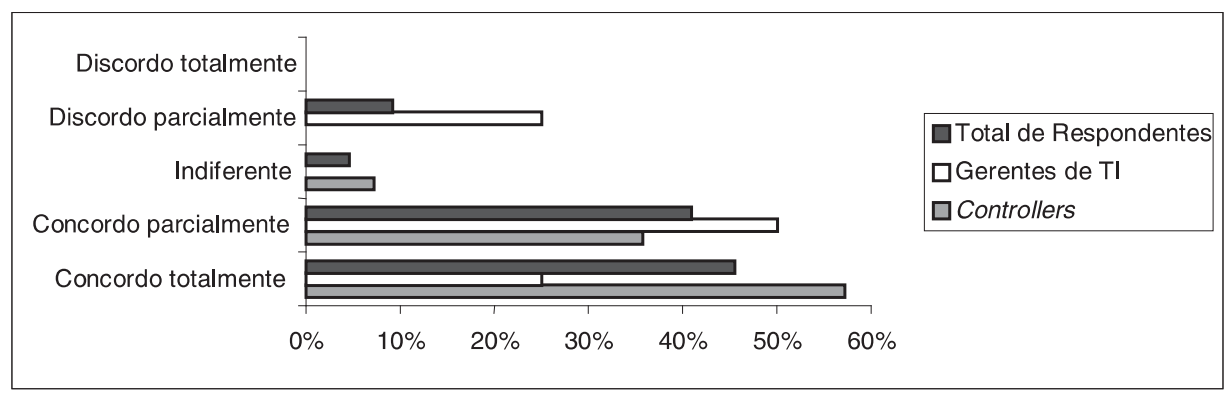

\section{Quadro 4: Alinhamento Estratégico da TI sobre Retorno de Investimentos}

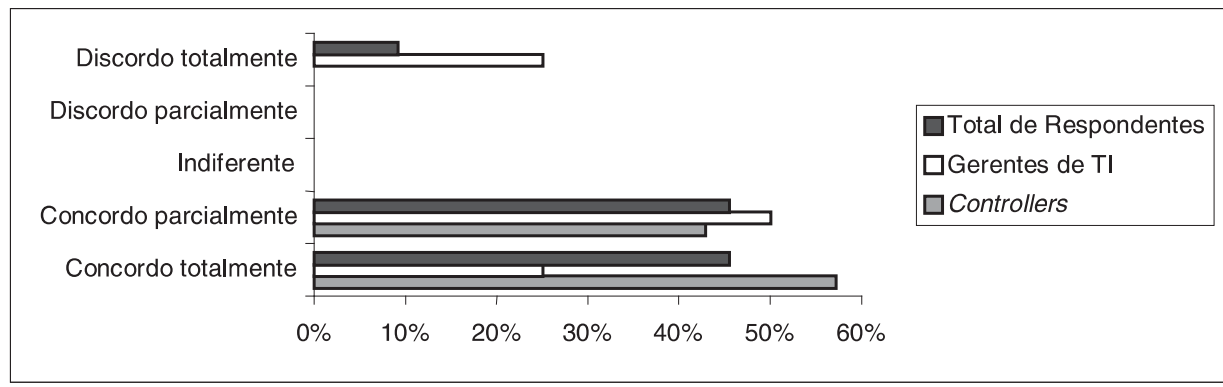

Quanto à gestão de Banco de Dados, as opiniões dos profissionais de TI são divididas com relação ao fato de a Controladoria fornecer conceitos para a modelagem, construção e gestão das bases de dados individuais e corporativas pelos profissionais de TI; mas eles concordam que ela participa do processo de escolha, implantação e acompanhamento das ferramentas de análise como Data Warehouse e Data Mart, por exemplo. Da mesma forma, 82\% dos entrevistados concordam que a Controladoria participa do processo de escolha, implementação e acompanhamento de tecnologias de gestão voltadas à integração dos sistemas de informação, tais como ERP, EIS, SCM, BI, CRM, entre outros. Assim, a Controladoria atua como departamento responsável pelas informações geradas nos sistemas de informações da organização, mas ainda não atua na concepção dos bancos de dados que armazenam e fornecem tais informações. Neste sentido, 
cabe aos Controllers desenvolverem-se com o propósito de participarem desse processo, visando à otimização da criação e utilização dos bancos de dados.

Os resultados que compõem esta análise podem ser constatados a seguir nos Quadros 5 a 7:

\section{Quadro 5: Gestão de Banco de Dados (Modelagem)}

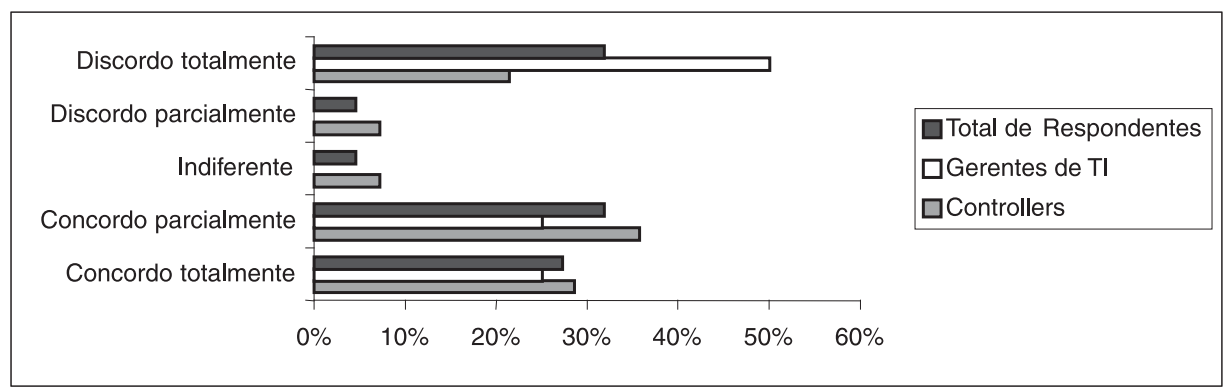

\section{Quadro 6: Gestão de Banco de Dados (Ferramentas)}

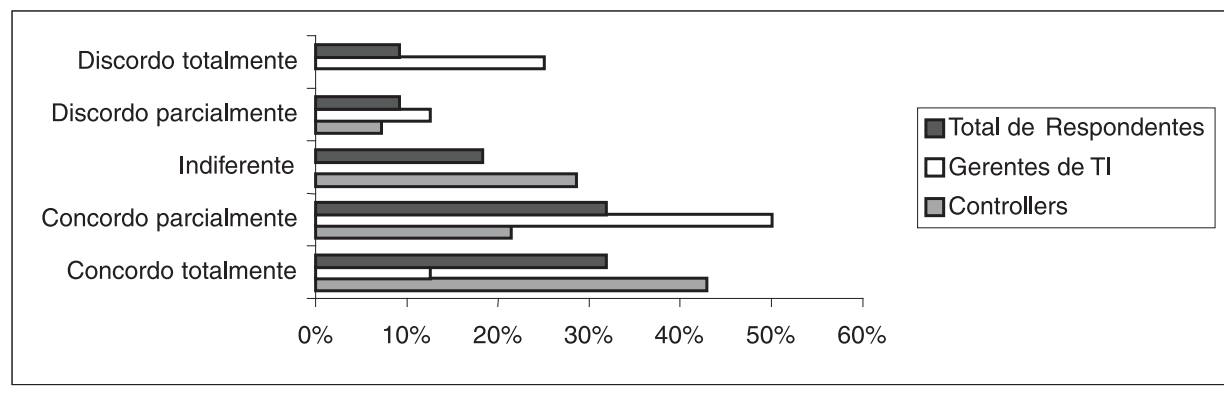

Quadro 7: Gestão dos Sistemas Integrados

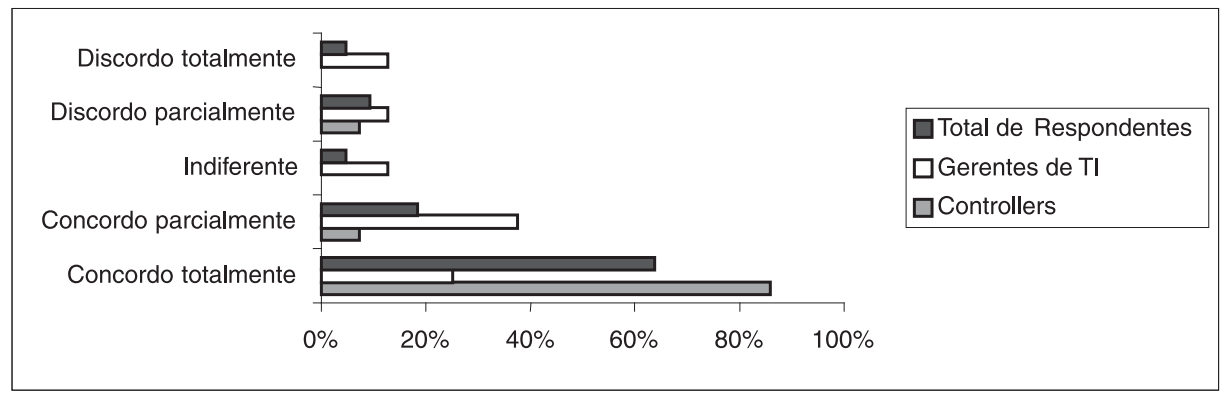

Diante da gestão dos recursos humanos subordinados a área de TI, existem divergências entre Controllers e Gerentes da área de TI. Dos Controllers, 50\% concordam que a Controladoria fornece suporte à área de TI na administração, avaliação, compensação e no treinamento e desenvolvimento de recursos 
humanos subordinados a essa área; no entanto 75\% dos profissionais de TI discordam dessa afirmação. Contudo, 73\% do total de respondentes concordam que a Controladoria atua como órgão motivador dos recursos humanos a ela subordinados e envolvidos em projetos da área de TI.

Assim, para reverter o resultado apresentado nos Quadros 8 e 9, os controles pessoais citados por Schimdt (2003. p. 34), enquanto método da Controladoria que orienta seus colaboradores ao automonitoramento de resultados, precisam tornar-se mais claros para os profissionais da área de TI, com o escopo de compartilharem das mesmas opiniões.

\section{Quadro 8: Gestão de Recursos Humanos}

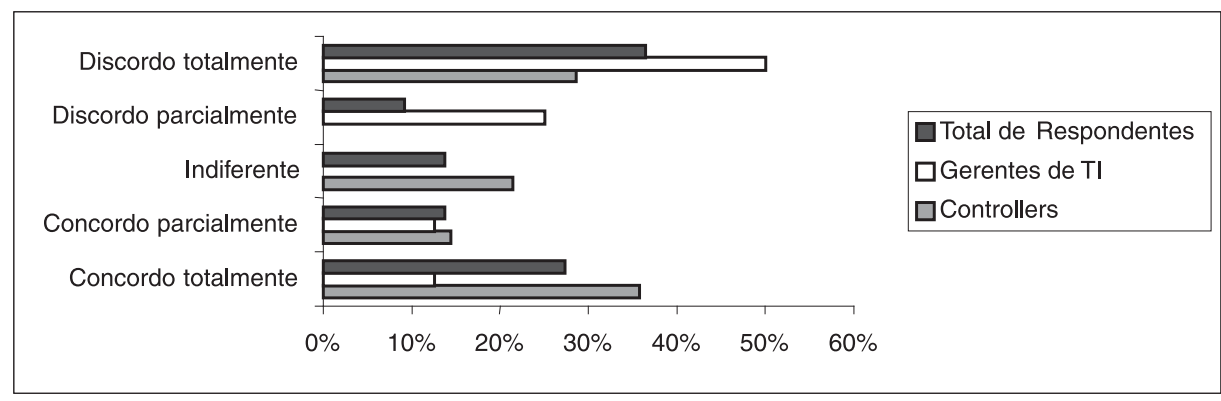

\section{Quadro 9: Comportamento Organizacional}

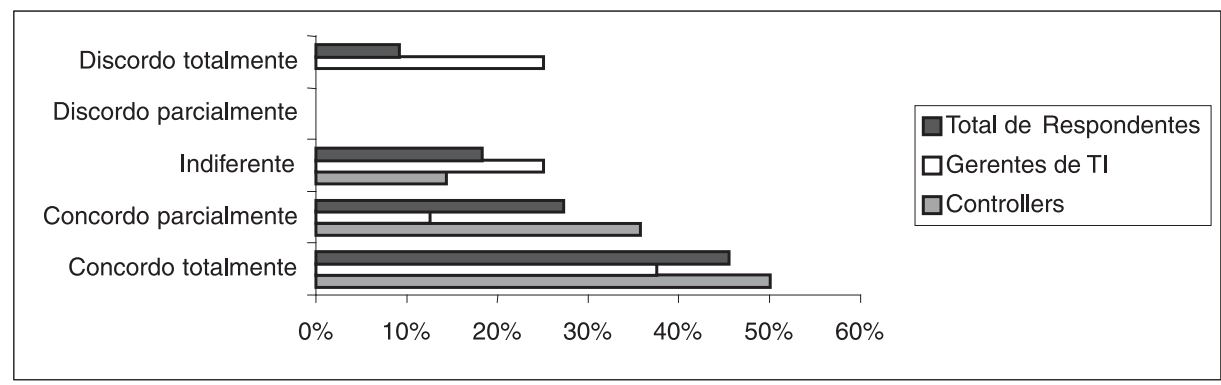

Em relação às Métricas Aplicadas à Tecnologia de Informação, existe aproximação entre os profissionais das áreas, no sentido de que a Controladoria auxilia a área de TI no uso de métricas para gestão de áreas de negócio, tais como Benchmarking e Balanced Scorecards - BSC, também participando na seleção e implementação destas métricas. Apenas 18\% dos respondentes discordam desta afirmação.

Segundo Schmidt (2002), os controles de gestão e de resultados utilizados pela Controladoria, por se tratar de sistema qualitativo e quantitativo, são muito utilizados por outras áreas da organização; mas segundo se pode observar no Quadro 10, 
embora a maioria dos CIOs concordem com esta utilização, grande parte de gestores de TI ainda tem dificuldade para assimilar os conceitos fornecidos pela Controladoria.

\section{Quadro 10: Métricas Aplicadas à Tecnologia da Informação}

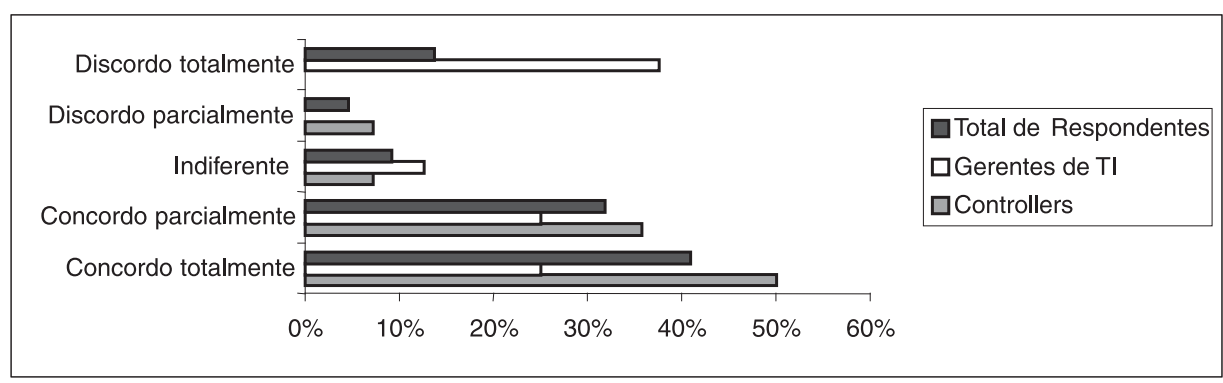

Na gestão da segurança, as opiniões também são divergentes entre profissionais das áreas de Controladoria e TI. Diante da afirmativa: a Controladoria fornece conceitos necessários para a implementação de uma estrutura de controle para TI, participando junto à área de auditoria de sistemas, na adoção de metodologias adequadas à redução das contingências em TI e dos riscos e ameaças às organizações, $71 \%$ dos profissionais de Controladoria concordaram com a afirmativa, enquanto 63\% dos profissionais de TI se mostraram contrários ou indiferentes. A divergência apresentada no Quadro 11 ocorre devido ao questionamento que se faz quanto à independência dos profissionais de Auditoria Interna, que normalmente são subordinados à área de Controladoria das organizações, conforme aponta Boynton, Johnson e Kell (2002).

\section{Quadro 11: Gestão da Segurança}

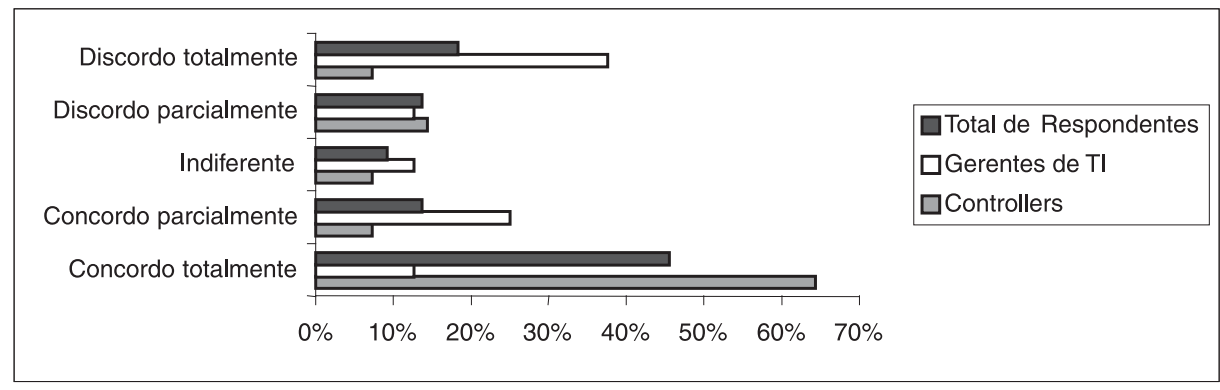

Focalizando-se a Gestão de E-Business, 93\% dos Controllers afirmaram prestar suporte à gestão da TI na mensuração e acompanhamento de projetos de e-business (planejamento tributário, por exemplo). No entanto, 50\% dos profissionais de TI não concordam com este suporte, sendo que 25\% 
responderam ser indiferentes a esta informação, conforme exposto no Quadro 12. Isto pode refletir as dificuldades existentes na avaliação do retorno de investimento deste tipo de projeto, que depende de legislações tributárias definidas e alterações significativas nas estratégias de negócio, segundo pesquisa realizada por Marcellos (2002) sobre os aspectos tributários do e-commerce no Brasil.

\section{Quadro 12: Gestão de E-Business}

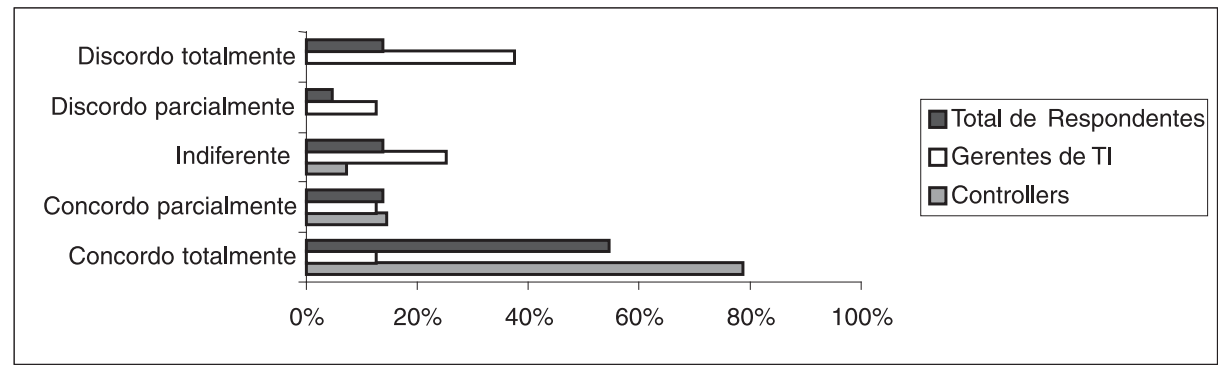

Na Gestão de Documentos, 93\% dos Controllers afirmaram auxiliar a área de TI na gestão da informação existente sob a forma eletrônica, em termos do seu ciclo de vida dentro das organizações (Workflow) e na indexação e arquivo da documentação previamente existente em papel ou em qualquer outro suporte (Gestão Documental). Entre os profissionais de TI, 50\% afirmaram concordar com este auxílio, e 13\% se mostraram indiferentes. Considerando a responsabilidade da Controladoria mencionada por Mosimann e Fisch (1999, p. 91) quanto à preparação e apresentação de relatórios gerenciais e controle de todos os livros e registros exigidos pelos diversos órgãos de Fiscalização Pública, o Quadro 13 revela que alguns profissionais de TI não assumem tal responsabilidade, deixando exclusivamente para os Controllers esta função.

\section{Quadro 13: Gestão de Documentos}

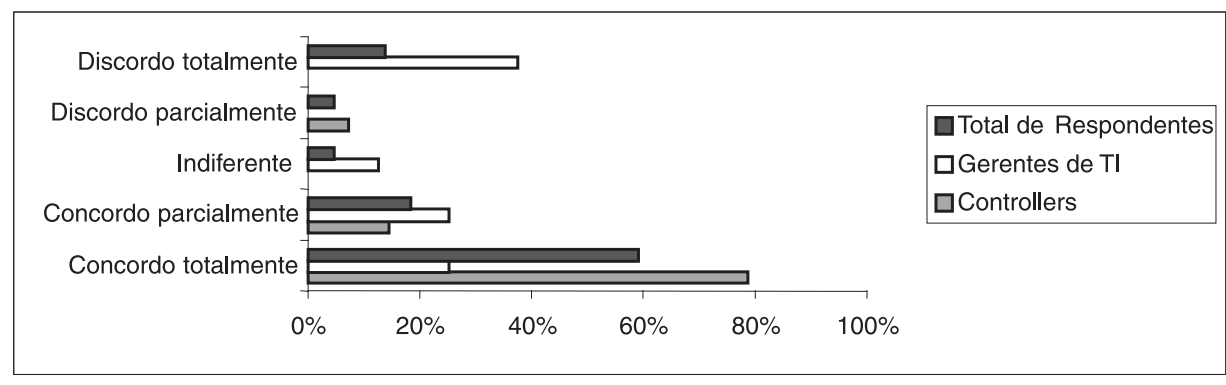

De todas as afirmações apresentadas aos entrevistados, a mais aceita pelos 
Controllers diz respeito à Gestão de Contratos. Diante da afirmativa: a Controladoria fornece o suporte necessário à TI nos processos de terceirização e gestão de contratos de fornecimento de serviços e equipamentos, na viabilidade financeira, controle do faturamento por meio de procedimentos de medição e acompanhamento, $100 \%$ dos gerentes da área de Controladoria e $86 \%$ dos profissionais de TI se mostraram favoráveis à afirmação. Isto confirma a aplicação, por parte dos profissionais da Controladoria, de seus conhecimentos financeiros e contábeis para o planejamento financeiro da área de Tecnologia da Informação.

O cenário assinalado no Quadro 14 revela também que a tendência de terceirização da Tecnologia da Informação nas organizações, apontada por Teixeira Jr. (2004) na Revista Exame, em sua matéria de capa "Tecnologia da Informação: dá para se livrar dela?”, pode ser verificada junto aos profissionais de TI e Controladoria da amostra selecionada.

\section{Quadro 14: Gestão de Contratos}

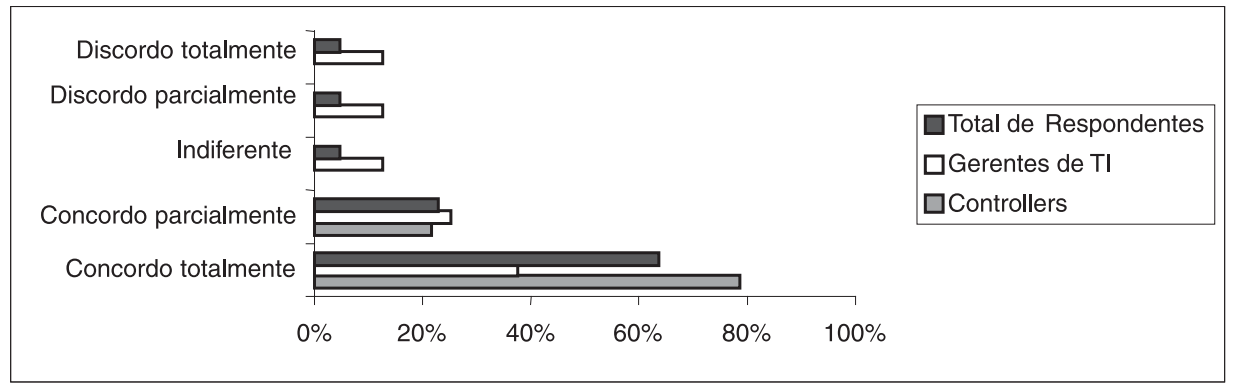

\section{Considerações Finais e Sugestões para Futuras Pesquisas}

Os resultados da pesquisa apresentados anteriormente, quando tabulados considerando a média de opiniões entre Controllers e Gerentes de TI, permitem a visão conjunta das variações das respostas obtidas (Quadro 15). É importante salientar que esta tabulação poderia apresentar outro resultado, caso fosse dado peso às respostas dos profissionais de Controladoria e Informática em função do conhecimento do respondente com o assunto apresentado. 


\section{Quadro 15: Visão Conjunta/Integrada da Média de Opiniões sobre os Temas}

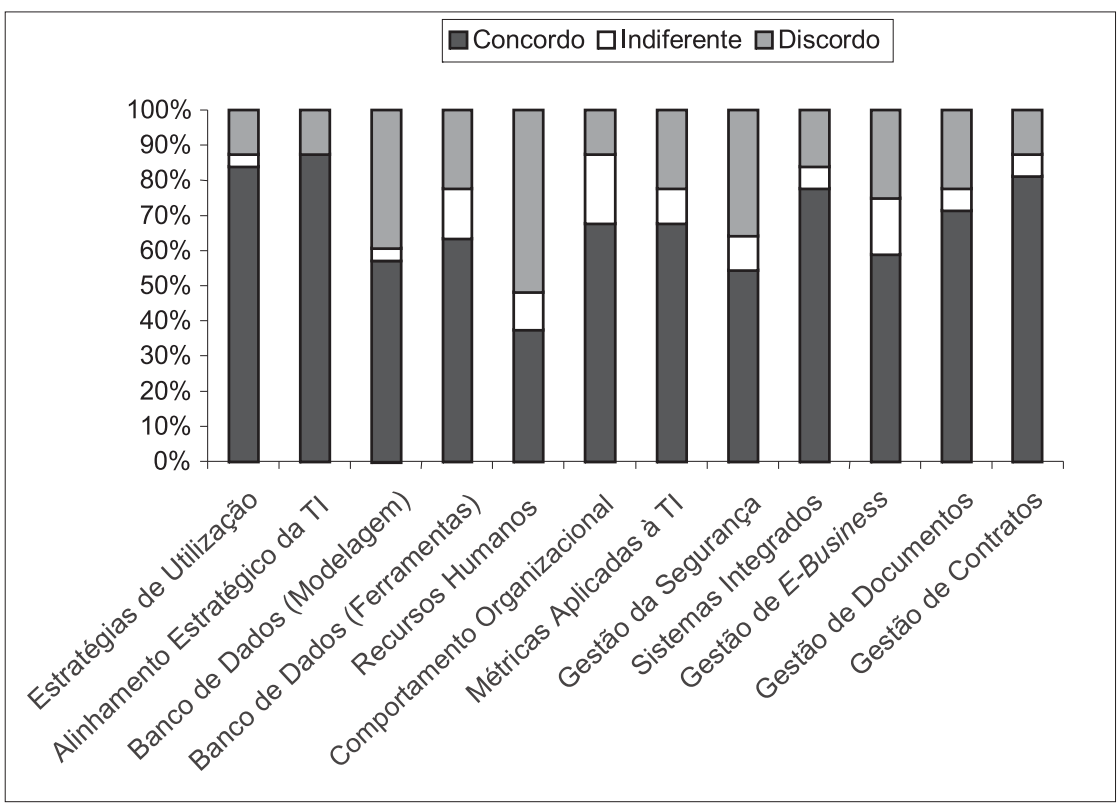

Os dados da pesquisa demonstram que os Gestores de TI e os Controllers concordam com a contribuição da Controladoria na Gestão da Tecnologia da Informação, havendo menor concordância principalmente nos seguintes aspectos:

a) Gestão de Recursos Humanos;

b) Modelagem de Banco de Dados;

c) Gestão de Segurança.

No primeiro aspecto (Recursos Humanos), o resultado indica que a Controladoria não está tornando transparente sua orientação no processo de gestão dos Recursos Humanos da área de TI. O emprego de metodologias de avaliação e compensação, assim como incentivos para o desenvolvimento e treinamento de pessoal são comumente atribuídos por esta área, devido principalmente à sua atuação no processo de Planejamento (desenvolvimento e treinamento) e Controle (avaliação e compensação de recursos humanos). Verifica-se neste sentido a necessidade de uma investigação que demonstre a transparência das ações da Controladoria na gestão dos Recursos Humanos da organização.

Em relação ao segundo aspecto, a falta de conhecimento técnico necessário 
aos profissionais de Controladoria para fornecer os subsídios de modelagem dos bancos de dados dos sistemas de informações gerenciais aparentemente pode ser uma justificativa para o resultado encontrado, sendo necessária a realização de pesquisas adicionais para se comprovar tal hipótese.

No terceiro item assinalado, verifica-se o impacto da divergência de opiniões existente acerca da subordinação da área de Auditoria (ligada à Gestão de Segurança) em relação à área de Controladoria das organizações. O que se pode observar na da pesquisa conceitual é uma forte caracterização de independência, quando se trata de segurança dos sistemas de informações, embora seja apontada a responsabilidade de controle por parte da Controladoria. Neste sentido, as ações que definem o processo Gestão da Segurança devem orientar adequadamente a participação de todos os envolvidos.

A presente pesquisa procurou demonstrar a importância do papel do Controller na gestão da Tecnologia da informação, justificando novas pesquisas no sentido de se investigar o impacto das decisões destes gestores nas áreas de tecnologia da organização.

\section{Artigo recebido em 13.12.2003. Aprovado em 17.04.2004.}

\section{ReferênCIAS Bibliográficas}

ALMEIDA, L.B.;

PARISI, C.;

PEREIRA, C.A.

Controladoria. In: CATELLI, A (Coord.). Controladoria: uma abordagem da gestão econômica. 1 . ed. São Paulo: Atlas, 1999. p. 373, 375, 376.

ARAUJO, D. N. do

Modelo Lógico de Banco de Dados proposto para uma Contabilidade de Partida Múltipla. Adcontar - Revista do Centro de Estudos Administrativos e Contábeis, Belém, v. 4 , n. 2, p. 27-44, nov. 2003.
BANHAM, R.

One way to bridge the CFO-CIO divide: Bring a third party into the conversation. CFO: Magazine for Sênior Financial Executives. New York, v. 19, Issue 4, p40, 6p, 4c. p. 40 46, spring 2003.

BOYNTON, W. C.;

JOHNSON, R. N.;

KELL, W. G.

Auditoria. 1. ed. São Paulo: Atlas, 2002. p. 181.

CRUZ, T.

Workflow: a tecnologia que vai revolucionar processos. 1. ed. São Paulo: Atlas, 1998. p. 115. 
IMONIANA, J. O.

Carrer Development in IT Auditing: Work Internship, Work Experience or Formal Educational Training. Revista Álvares Penteado. São Paulo. v. 5, n. 11, p. 9-23, abr. 2003.

JAMIL, G. L.

Repensando a TI na Empresa Moderna. 1. ed. Rio de Janeiro: Axcel, 2001. p. 387.

JOHN, D. A.

Team CIO. CIO Insight. Disponível em: <http://www.cioinsight.com/ article2/ 0,1397,1457532,00.asp>. Acesso em: 06 jun. 2004.

LAUDON, K. C;

LAUDON, J. P.

Gerenciamento de Sistemas de Informação. 3. ed. Rio de Janeiro: LTC, 2001. p. 7, 170, 228, 344.

\section{LAURINDO, F. J. B.}

Tecnologia da informação: eficácia nas organizações. 1. ed. São Paulo: Futura, 2002. p. 29, 33, 79.

MANÃS, A. V.

Gestão de tecnologia e inovação. 3 . ed. São Paulo: Érica, 2001. p. 159.

MARCELLOS, P.S.

Aspectos tributários do e-commerce e a figura do fiscal de tributos inerente ao ambiente globalizado brasileiro atual. 2002. 166 f. Dissertação (Mestrado em Controladoria e Contabilidade Estratégica) - Centro Universitário Álvares Penteado UNIFECAP, São Paulo.

MARIANNE, B.

The CIO as a Business Partner. Internet World. Norwalk, v. 8, Issue 9, p. 41, 42, Sept. 2002
MOSIMANN, C. P.;

FISCH, S.

Controladoria: seu papel na administração de empresas. 2. ed. São Paulo: Atlas, 1999. p. 89, 91.

OLIVEIRA NETO, J. D. de;

RICCIO, E. L.

Desenvolvimento de um instrumento para mensurar a satisfação do usuário de sistemas de informações. Revista deAdministração da Universidade de São Paulo. São Paulo, v. 38, n. 3. p. 230-241, jul./ago./set. 2003.

\section{PELEIAS, I. R.}

Desafios e possibilidades para o Contabilista no ambiente dos Sistemas Integrados. Revista Brasileira de Contabilidade, Brasília, Ano XXX, n. 132, p. 39-55, nov./dez. 2000.

RAJAJI, R.

Are you in tune with your CIO. Financial Executive. Florham Park, v. 12, Issue 4, p20, 7p. July/Aug. 1996.

STAIR, R. M.

Princípios de Sistemas de Informação. 2. ed. Rio de Janeiro: LTC, 1998. p. 13.

SCHMIDT, P. (Coord.)

Controladoria: agregando valor para o acionista. 1. ed. Porto Alegre: Bookman, 2002. p. 31, 34.

TEIXEIRAJr., S.

Tecnologia da Informação: dá para se livrar desse abacaxi? Revista Exame, São Paulo, ano 38, n. 2, ed. 810, p. 4554. 4 fev. 2004.

WANG, C. B.

O novo papel do executivo de informática. 1. ed. São Paulo: Makron Books, 1995. p. 58 